\title{
Construction of an insertional-inactivation cloning vector for Escherichia coli using a Rhodococcus gene for indigo production
}

\author{
STEPHEN HART and David R. WOOds* \\ Department of Microbiology, University of Cape Town, Rondebosch, 7700, South Africa
}

(Received 10 June 1991; revised 20 August 1991; accepted 16 September 1991)

\begin{abstract}
pSLH8, an insertional-inactivation cloning vector for Escherichia coli has been constructed by inserting a pigment gene (probably encoding an indole dioxygenase) from Rhodococcus sp. ATCC 21145 into pUC18. Wild-type E. coli colonies containing pSLH8 produce insoluble indigo and turn dark blue on unsupplemented $L B$ agar. Insertion of DNA fragments into the unique BamHI, EcoRI, EcoRV, HindIII, PstI, SphI and SstI polylinker cloning sites disrupts the reading frame of the fully sequenced pigment gene and results in unpigmented colonies. pSLH8 may be an attractive alternative to pUC18 and similar plasmids because it does not require specifically mutated host strains or an expensive substrate for colour development.
\end{abstract}

\section{Introduction}

Hill et al. (1989) discovered a DNA fragment from a Rhodococcus species which stimulated the production of an insoluble blue pigment in wild-type Escherichia coli strains. Hart et al. (1990) found that a single open reading frame encoding a hypothetical protein of $42560 \mathrm{Da}$ was necessary and sufficient for pigment production. A database search identified no similar protein sequence and gave no clues about the possible enzymic activity specified by the cloned Rhodococcus gene. The pigment has been identified as indigo (blue) and a smaller amount of indirubin (red), both of which are probably derived from indole, a degradation product of tryptophan (Hart et al., 1992). The cloned Rhodococcus gene probably encodes an indole dioxygenase.

Here we describe a cloning vector derived from pUC18 (Vieira \& Messing, 1982) in which a modified 'indigo gene' replaces $l a c Z \alpha$ as the reporter gene.

\section{Methods}

Bacterial strains and plasmids. These are listed in Table 1. LB agar (Maniatis et al., 1982) with ampicillin (Ap) $(100 \mu \mathrm{g} \mathrm{ml}-1)$ or chloramphenicol $(\mathrm{Cm})\left(25 \mu \mathrm{g} \mathrm{ml}^{-1}\right)$ was used for all experiments. Blue to blue-grey pigment-producing $E$. coli colonies were observed after overnight incubation at $37^{\circ} \mathrm{C}$ followed by $8-20 \mathrm{~h}$ incubation at room temperature. Addition of tryptophan or indole $(0.5-1 \mathrm{~mm})$ to the medium resulted in increased pigment production (Hart et al., 1992).

Abbreviations: Ap, ampicillin; bla, $\beta$-lactamase; $\mathrm{Cm}$, chloramphenicol.
Pigment production was also enhanced by the addition of lactose $(0.2 \%, w / v)$ or IPTG $(0.3 \mathrm{mM})$ and was repressed by the addition of glucose presumably because of catabolite repression of tryptophanase (Hart, 1991).

Preparation of plasmid DNA. Plasmid DNA was prepared from $E$. coli strains by the alkaline lysis method of Ish-Horowicz \& Burke (1981). Large-scale plasmid preparations were purified by $\mathrm{CsCl}$ equilibrium gradient centrifugation (Maniatis et al., 1982). Plasmid preparations for DNA sequencing were treated with RNAase A (Maniatis et al., 1982) followed by a phenol/chloroform extraction and ethanol precipitation (Maniatis et al., 1982).

Subcloning procedures. Restriction endonucleases (BoehringerMannheim, Anglian Biotechnology or BRL) were used as described by Maniatis et al. (1982). DNA fragments were gel-purified from lowmelting-point agarose (Seaplaque) gels and separated from the agarose with 'Geneclean' (Bio 101) according to the manufacturer's instructions. Blunt ends were generated by filling in with T4 DNA polymerase I (Maniatis et al., 1982). The DNA products of ligation reactions (Maniatis et al., 1982) were transformed into competent cells (Chung \& Miller, 1988). Transformants were selected on LB agar plates containing the appropriate antibiotic.

Oligonucleotide primers. Primers were obtained from Professor D. P. Botes (Department of Biochemistry, University of Cape Town, South Africa). A 17-mer synthetic primer with the sequence 5'CGAAGGCCGGTACCAGG-3', complementary to nucleotide positions 849-832 at the 5 -end of the pigment gene (Hart et al., 1990) was designed for nucleotide sequencing into the region upstream of the pigment gene to verify constructs from subcloning and mutagenesis procedures.

DNA sequencing. DNA sequencing was done by the dideoxy chainterminating method of Sanger $e t$ al. (1977) with a 'Sequenase' kit (US Biochemicals Corp.) following the manufacturer's instructions. The DNA was radiolabelled with $\left[{ }^{35} \mathrm{~S}\right] \mathrm{dATP}\left(>1000 \mathrm{Ci} \mathrm{mmol}^{-1}\right.$; Amersham). 
Table 1. Bacterial strains and plasmids

\begin{tabular}{|c|c|c|}
\hline $\begin{array}{l}\text { Strain or } \\
\text { plasmid }\end{array}$ & $\begin{array}{l}\text { Genotype or } \\
\text { phenotype* }\end{array}$ & $\begin{array}{l}\text { Source or } \\
\text { reference }\end{array}$ \\
\hline E. coli 3.300 & $\begin{array}{l}\text { lac } 22 \lambda^{-} \text {relAl } \\
\text { spoTl thi-l }\end{array}$ & Pardee et al. (1959) \\
\hline E. coli LK 111 & lacI lacZ $\Delta \mathrm{M} 15$ lac $Y^{+}$ & Zabeau \& Stanley (1982) \\
\hline E. coli WK6 & $\begin{array}{l}\Delta(\text { lac-proAB }) \text { galE } \\
\text { strA } / \mathrm{F}^{\prime} \text { laq } I^{\natural} \text { lacZ } \Delta \mathrm{M} 15 \\
\text { pro } A^{+} B^{+}\end{array}$ & Stanssens et al. (1989) \\
\hline E. coli WK6 mutS & 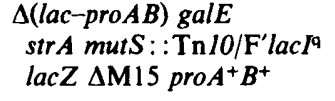 & Stanssens et al. (1989) \\
\hline pKS3 & $\mathrm{Ap}^{r} \mathrm{Lac}^{-} \mathrm{Pig}^{+}$ & Hart et al. (1990) \\
\hline pKSmut & $\mathrm{Ap}^{r} \mathrm{Lac}^{-} \mathrm{Pig}^{+}$ & This study \\
\hline pMa3 & $\mathrm{Ap}^{r} \mathrm{Cm}^{\mathrm{s}}$ & This study \\
\hline pMa5-8 & $\mathrm{Ap}^{r} \mathrm{Cm}^{\mathrm{s}}$ & Stanssens et al. (1989) \\
\hline pMc5-8 & $\mathrm{Ap}^{s} \mathrm{Cm}^{r}$ & Stanssens et al. (1989) \\
\hline pSLHI & $\mathrm{Ap}^{\mathrm{r}} \mathrm{Lac}^{-} \mathrm{Pig}^{+}$ & This study \\
\hline pSLH4 & $\mathrm{Ap}^{r} \mathrm{Lac}^{-} \mathrm{Pig}^{+}$ & This study \\
\hline pSLH8 & $\mathrm{Ap}^{r} \mathrm{Lac}^{-} \mathrm{Pig}^{+}$ & This study \\
\hline pSmu 25 & $\mathrm{Ap}^{\mathrm{s}} \mathrm{Cm}^{\mathrm{r}}$ & This study \\
\hline
\end{tabular}

* Pig, pigment production.

\section{Results and Discussion}

Introduction of an SphI site at the start codon of the indigo gene by site-directed mutagenesis

This procedure was performed as described by Stanssens et al. (1989) using the phasmids pMa5-8 and pMc5-8 in a gapped-duplex approach to site-directed mutagenesis (Kramer et al., 1984). pMa5-8 and pMc5-8 contain, in addition to a ColE1-type origin of replication, the $\mathrm{fl}$ filamentous phage origin of replication. Superinfection with the helper phage makes it possible to package one specific strand of the phasmids into phage rods. Phasmid pMa5-8 confers resistance to Ap and contains an amber mutation in the cat gene. The complementary vector pMc5-8 confers resistance to $\mathrm{Cm}$ and contains an amber mutation in the $\beta$-lactamase (bla) gene. E. coli WK6 was used as a recipient for the phasmids and their derivatives. E. coli WK6mutS is a mismatch-repair-deficient strain that is unable to suppress amber mutations. Strains WK6 and WK6mutS were regularly inoculated onto minimal medium to select for the pro marker present on the $\mathrm{F}^{\prime}$ episome.

The fragment of DNA between the SmaI site located within the pigment gene in the plasmid pKS3 and the HindIII site of the multiple cloning cassette of pKS3 was subcloned into the SmaI/HindIII sites in the multiple cloning site of pMa5-8 $\left(\mathrm{Ap}^{\mathrm{r}} \mathrm{Cm}^{\mathrm{s}}\right)$ to produce the phasmid pMa3 (Fig. 1), and transformed into $E$. coli WK6. Gapped-duplex DNA was formed by hybridizing pMa3 ssDNA with denatured pMc5-8 $\left(\mathrm{Ap}^{3} \mathrm{Cm}^{\mathrm{r}}\right)$ DNA which was digested with HindIII and SmaI. A 34-mer oligonucleotide (5'- ACA CCG GAG GAA AGC ATG CAC

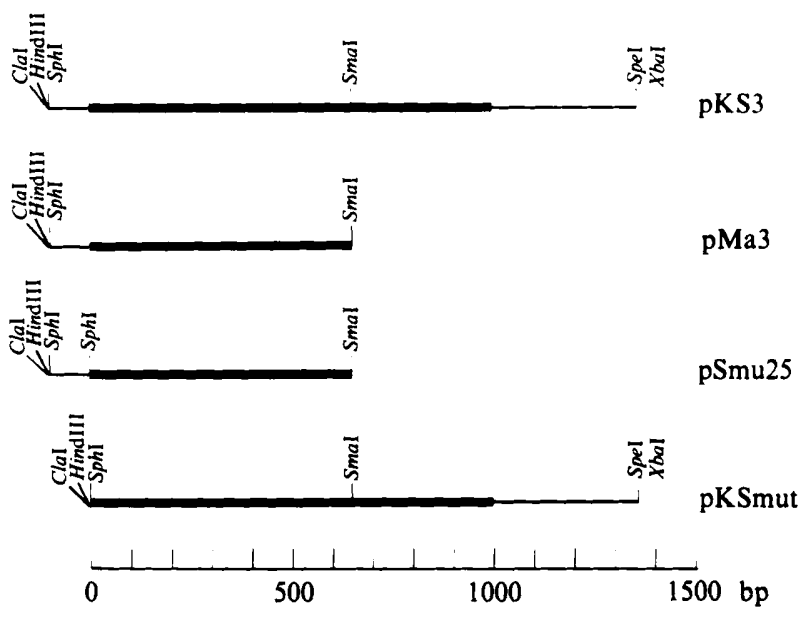

Fig. 1. Construction of pKSmut by site-directed mutagenesis. pMa3 was made by subcloning the HindIII/SmaI fragment of pKS3 (750 bp) into the plasmid pMa5-8. A new SphI site was formed at the start of the 1161 bp coding sequence (black box) in pSmu25. pKSmut was made by replacing the SphI/Smal fragments of pK33 with the restriction fragment between the newly-created SphI site and the SmaI site of pSmu25.

ATC ACC CGC ACC G-3') complementary to positions 778-808 of the pigment gene (Hart et al., 1990), containing three mismatches (bold type) and a SphI site (underlined) was used as the mutagenic primer. This primer enabled the creation of an SphI site overlapping the ATG start codon of the pigment gene at position 791-793 [numbering of Hart et al. (1990)]. After annealing of the pMa3-pMc5-8 heteroduplex with the mutagenic primer, the gap was filled in, ligated and the DNA transformed into $E$. coli WK6mutS. The strands of the hybrid plasmid were allowed to segregate by two 
(a)

pUC18 lacOP--EcoRI SstI KpnI SmaI BamHI XbaI Sall PstI SphI HindIII--

pSLH1 lacOP-EcoRI SstI KpnI SmaI BamHI Xbal Sall-C TGC AGG CGA TAA GCT TGC ATG CAC--
pSLH4 lacOP--EcoRI SstI KpnI SmaI BamHI Xhal Sall-C CAC-

mccl 5'- CT $\frac{P s t I}{\text { CTG CAG CTG GAT CCG }} \frac{\text { BamHI }}{\text { GAT ATC CA }} \quad-3^{\prime}$

mec2 3 '-TCG AGA GAC GTC GAC CTA GGC CTA TAG GTT CGA-5'

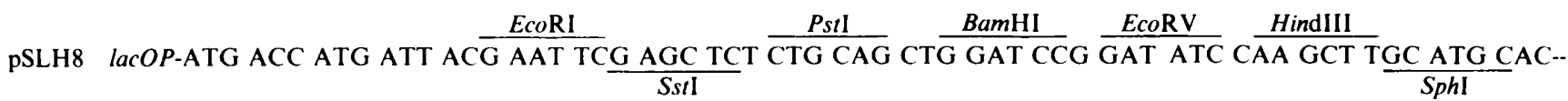

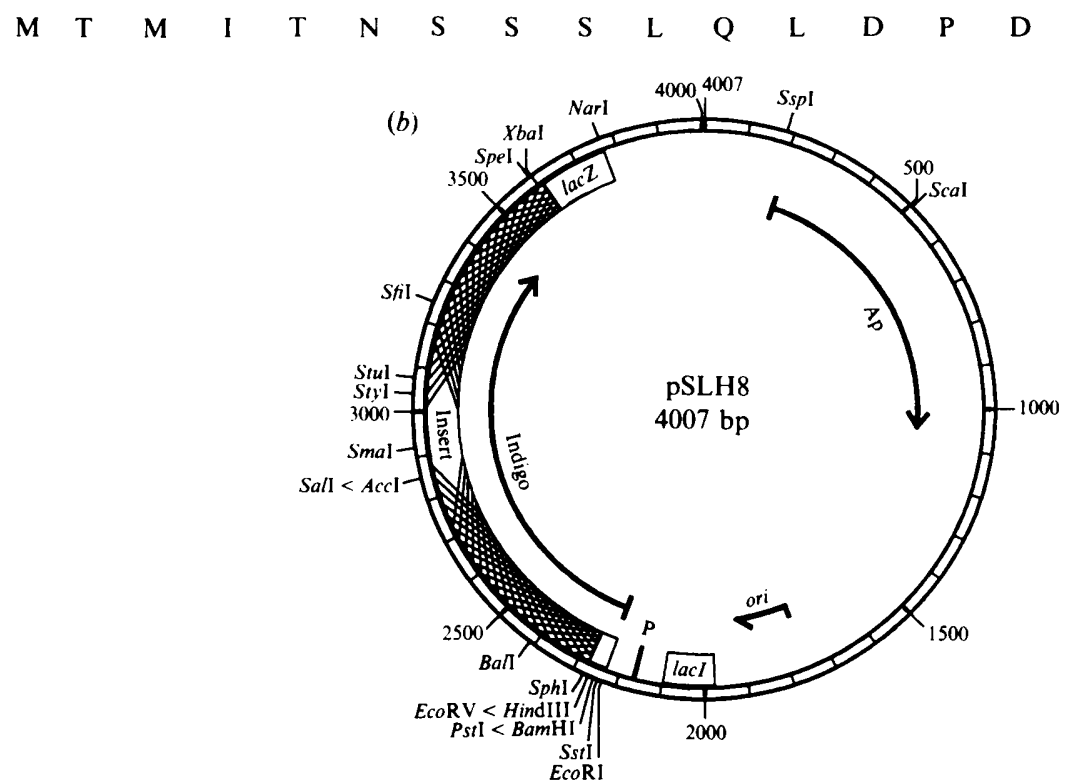

Fig. 2. (a) Cloning cassette regions of the plasmids pUC18, pSLH1, pSLH4 and pSLH8 showing restriction sites and relevant codons. pUC18; underlined restriction sites occur in the pigment gene. pSLH1; ClaI/XbaI fragment of pKSmut (Fig. 1) containing the pigment gene, blunted and subcloned into the blunted SphI/HindIII sites of pUC18, showing rare codons (underlined), stop codon (*) and start codon $(>$ ) of the pigment gene coding sequence. pSLH4; PstI/SphI fragment of pSLHI deleted and the vector blunted and religated to remove rare codons and nonsense codon. $\mathrm{mcc} 1 / \mathrm{mcc} 2$; synthetic multiple cloning cassette with $5^{\prime}$ Sst I and $3^{\prime}$ HindIII compatible overhangs. pSLH8; mccl/mcc2 subcloned into SstI/HindIII-digested pSLH1. Restriction enzymes with single cutting sites in the multiple cloning cassette of pSLH8 are: BamHI, EcoRI, EcoRV, HindIII, PstI, SphI and SstI. Restriction enzymes with single cutting sites in the pigment gene of pSLH8 are: $A c c \mathrm{I}, B a l \mathrm{I}, B d r \mathrm{I}, B s p \mathrm{MII}, D r d \mathrm{II}, E c o B I, E c o \mathrm{KI}, E c o \mathrm{R} 1241, M l u \mathrm{I}, N r u \mathrm{I}, P p u \mathrm{MI}, S a l \mathrm{I}, S f i \mathrm{I}$, SgrAI, SmaI, StuI, StyI and StySPI. (b) pSLH8 insertional-inactivation cloning vector showing Rhodococcus DNA insert (hatched box), pigment gene coding sequence $(\leftarrow)$, remains of lac $Z^{\prime} \alpha$-fragment (lacZ), lacI, PlacZ (P), ori and Ap ${ }^{r}$ genes, and cloning cassette (open box).

rounds of replication and transformation. $\mathrm{Cm}^{\mathrm{r}}$ transformants were selected and the presence of the mutation in one of the transformants, designated pSmu25 (Fig. 1), was confirmed by restriction endonuclease digestion and nucleotide sequencing using the 17 -mer synthetic primer. The restriction fragment between the newly created $S p h I$ site and the internal SmaI site of the pigment gene fragment in pSmu25 was used to replace the $750 \mathrm{bp}$ SmaI/SphI fragment of pKS3 to produce pKSmut (Fig. 1). pKSmut produced normal amounts of pigment.
Construction and characterization of cloning vectors pSLHI and $p S L H 4$

pSLH1 (Fig. 2) was generated by ligating the ClaI/XbaI fragment of pKSmut (Fig. 1) into SphI- and HindIIIdigested pUC18. All ends were blunted with T4 DNA polymerase I. Plasmid pSLH1 was designed so that the coding sequence of the pigment gene was in-frame with the lac $Z^{\prime} \alpha$ coding sequence of pUC18. pSLH4 was generated by deletion of the $P s t \mathrm{I} / S p h \mathrm{I}$ fragment in the 
multiple cloning site of pSLH1 to remove the in-frame termination codon and rare codons (Fig. 2).

The prototype insertional-inactivation cloning vector pSLH1 contained an in-frame TAA termination codon adjacent to the HindIII site in the multiple cloning cassette as well as the rarely used codons AGG and CGA (underlined in Fig. 2). The presence of these codons, however, did not prevent pigment production in $E$. coli LK111(pSLH1) although the level of production appeared to be lower than that of other pigment-producing strains such as $E$. coli LK111(pKS3). In contrast to $E$. coli LK111(pSLH1), E. coli $3.300(\mathrm{pSLH} 1)$ cells produced only slight amounts of pigment even after several days incubation at room temperature. Production of pigment in LK111 may be due to translational coupling (Schümperli et al., 1982) or suppression. The nonsense and rare codons from the coding sequence in pSLH 1 are deleted in pSLH4 (Fig. 2) but the reading frame is maintained, resulting in an improved level of pigment production by both $E$. coli LK111 and 3.300. pSLH4, however, contained only three unique cloning sites, EcoRI, SacI and BamHI in the multiple cloning cassette (Fig. 2).

\section{Construction and characterization of the insertional- inactivation cloning vector, $p S L H 8$}

For the construction of pSLH8, a multiple cloning cassette was made with two complementary oligonucleotides, mccl and mcc2, which are shown in Fig. 2 in the annealed form with ssDNA overhangs at either end which were complementary to overhangs generated by HindIII or SstI, respectively. The nucleotide sequence of the cloning cassette was designed to maintain the same reading frame between the upstream lac $Z^{\prime}$ coding sequence and the downstream pigment gene when subcloned into the SacI/HindIII sites of pSLH1 to create pSLH8. The reading frame of the multiple cloning cassette sequence was selected to contain codons which occur frequently in highly expressed genes of $E$. coli (Wada et al., 1990).

Annealing of the complementary oligonucleotides mccl and mcc2 was carried out in a mixture with approximately $250 \mathrm{pmol}$ of each oligonucleotide, $2 \mu \mathrm{l}$ $1.5 \mathrm{M}-\mathrm{KCl} / 0.1 \mathrm{M}-\mathrm{Tris} / \mathrm{HCl}, \mathrm{pH} 7 \cdot 5$, and water to a final volume of $20 \mu \mathrm{l}$. The annealing mixture was heated to $60{ }^{\circ} \mathrm{C}$ for $5 \mathrm{~min}$ then allowed to cool slowly to room temperature. The dsDNA molecule generated was ligated into pSLH1 in an equimolar ratio of multiple cloning cassette to vector and transformed into competent cells of $E$. coli. Plasmid DNA was prepared from transformants and analysed for the presence of the multiple cloning cassette by restriction endonuclease analysis on agarose gels.
The vector pSLH8 produced high levels of pigment and had a multiple cloning cassette with seven unique restriction sites (Fig. 2). The size of pSLH8 was determined from the compiled nucleotide sequence (pigment gene, pUC18, 'Bluescript' KS, synthetic cloning cassette) to be $4007 \mathrm{bp}$. Large-scale DNA preparations of pSLH8 from $E$. coli gave yields similar to pUC plasmids suggesting a high-copy-number of about 200 plasmid molecules per cell.

A trial insertional-inactivation experiment was performed by randomly subcloning PstI-digested $\lambda$ DNA into the unique PstI site in the multiple cloning cassette of pSLH8 (Fig. 2). Transformants were a mixed population of clearly identifiable blue and white colonies on LB Ap agar plates. Plasmid DNA was prepared from six of each type of transformant and digested with Pst I. Agarose gel analysis of the digestion products showed that all of the blue-pigmented transformants contained unmodified pSLH8 plasmid DNA whereas all of the plasmids from white transformants contained $\lambda$ DNA inserts. This demonstrated that pSLH8 was functioning as an insertional-inactivation cloning vector.

pSLH8 fulfills the basic requirements for cloning vectors in that it is small, has many unique restriction sites and an easily selectable phenotype. One of the advantages of this system is the ability of $E$. coli cells containing pSLH8 to produce the indigo pigment on commonly used LB Ap agar plates without the requirement for any further media substrate supplementation (there is always a possibility, of course, that a DNA fragment cloned in-frame could generate a functional pigment-producing enzyme).

All E. coli host strains transformed with pSLH8 should be capable of indigo production provided that they produce tryptophanase. Tryptophanase is expressed at a high level in most strains of $E$. coli although it is very sensitive to catabolite repression by glucose in the growth medium. Pigment production was repressed by glucose but enhanced by indole and tryptophan. It is not yet known if the pigment gene will function as a marker in other bacteria.

Alternative insertional-inactivation vectors using the melanin operon as a marker system (Altenbuchner, 1988; Tseng et al., 1990) have the disadvantage that melanin diffuses into the media and may make detection of recombinants difficult if large numbers of transformed colonies are close together on the surface of the agar. The indigo produced by the pSLH series of plasmids is almost entirely intracellular (Hill et al., 1989). In addition, a modified medium supplemented with tyrosine and $\mathrm{Cu}^{2+}$ ions was required for melanin production, which was detectable after $2 \mathrm{~d}$ (Tseng et al., 1990). In contrast, the indigo marker functions on LB agar and is detectable within $8 \mathrm{~h}$ with near maximal colouration after $20 \mathrm{~h}$. 
pSLH8 has properties which make it suitable for use as an expression vector. The plasmid has a high-copynumber and promoterless inserts may be expressed from the IPTG-inducible lacOP promoter, which drives pigment gene expression. This vector would also be useful for nucleotide sequencing. The high-copy-number facilitates plasmid purification and the known vector sequence ensures that it is not mistaken for the test sequence. The cloning cassette contains seven commonly used restriction sites, three of which generate $3^{\prime}$ overhangs and three $5^{\prime}$ overhangs which would facilitate shortening of the DNA insert with exonuclease III (Henikoff, 1984). The M13 reverse sequencing primer and the 17-mer primer described in this paper can be used for sequencing cloned DNA from both ends.

\section{References}

Altenbuchner, J. (1988). A new $E$. coli cloning vector containing a melanin marker for insertion screening. Nucleic Acids Research 16, 8710

Chung, C. T. \& Miller, R. H. (1988). A rapid and convenient method for the preparation and storage of competent bacterial cells. Nucleic Acids Research 16, 3580.

HART, S. (1991). Characterization of pigment production by Escherichia coli containing a cloned Rhodococcus gene. PhD thesis, University of Cape Town, South Africa.

HART, S., K IRBY, R. \& WoOds, D. R. (1990). Structure of a Rhodococcus gene encoding pigment production in Escherichia coli. Journal of General Microbiology 136, 1357-1363.

HART, S. KoCH, K. R. \& Woods, D. R. (1992). Identification of indigo-related pigments produced by Escherichia coli containing a cloned Rhodococcus gene. Journal of General Microbiology 138, 211216 .
HenikofF, S. (1984). Unidirectional digestion with exonuclease III creates targeted breakpoints for DNA sequencing. Gene 28, 351-359.

Hill, R. T., Hart, S. L., Illing, N., KIRBY, R. \& WoODS, D. R. (1989) Cloning and expression of Rhodococcus genes encoding pigment production in Escherichia coli. Journal of General Microbiology 135 , $1507-1513$.

ISH-HorowICZ, D. \& BURKE, J. F. (1981). Rapid and efficient cosmid vector cloning. Nucleic Acids Research 9, 2989-2998.

Kramer, W.. Drutsa, V., Jansen, H.-W., Kramer, B., Pflugfelder, M. \& FRITZ, H.-J. (1984). The gapped duplex DNA approach to oligonucleotide-directed mutation construction. Nucleic Acids Research 12, 9441-9456.

Maniatis, T., Fritsch, E. F. \& SAmbrook, J. (1982). Molecular Cloning: A Laboratory Manual. Cold Spring Harbor, NY: Cold Spring Harbor Laboratory.

Pardee, A. B., JaCOB, F. \& Monod, J. (1959). The genetic control and cytoplasmic expression of inducibility in the synthesis of $\beta$-galactosidase by Escherichia coli. Journal of Molecular Biology 1, 165-178.

SANGER, F., Nicklen, S. \& Coulson, A. R. (1977). DNA sequencing with chain-terminating inhibitors. Proceedings of the National Academy of Sciences of the United States of America 74, 5463-5467.

SCHÜMPERLI, D., MCKenNEY, K., SobIESKI, D. A. \& RosenberG, M. (1982). Translational coupling at an intercistronic boundary of Escherichia coli galactose operon. Cell 30, 856-871.

Stanssens, P., Opsomer, C., MCKeown, Y. M., Kramer, W., Zabeau, M. \& FrITZ, H.-J. (1989). Efficient oligonucleotide-directed construction of mutations in expression vectors by the gapped duplex DNA method using alternating selectable markers. Nucleic Acids Research 17, 4441-4454.

TSENG, H.-C., LIN, C.-K., HsU, B.-J., LeU, W.-M., WU LEE, Y.-H., Chiou, S.-J., Hu, N.-T. \& Chen, C. W. (1990). The melanin operon of Streptomyces antibioticus : expression and use as a marker in Gramnegative bacteria. Gene 86, 123-128.

Vieira, J. \& Messing, J. (1982). The pUC plasmids, an M13mp7derived system for insertion mutagenesis and sequencing with synthetic universal primers. Gene 19, 259-268.

Wada, K.-N., Aota, S.-I., Suchiya, R. Ishibashi, F., Gojobori, T. \& Toshimichi, I. (1990). Codon usage tabulated from the GenBank genetic sequence data. Nucleic Acids Research (supplement) 18 2367-2411.

ZabeaU, M. \& STANley, K. (1982). Enhanced expression of cro- $\beta$ galactosidase fusion proteins under the control of the $P_{r}$ promoter of bacteriophage lambda. EMBO Journal 1, 1217-1224. 